\title{
Discourse Analysis of the New Colombo Plan funded Australian Outbound Student Mobility Programs
}

\author{
Mila Arden \\ Victoria University, Melbourne, Australia \\ Email: mila.arden@live.vu.edu.au \\ Address: Footscray Park Campus, Ballarat Road, Footscray 3011
}

\section{Introduction}

This research concentrates on Outbound Student Mobility (OSM), which means that local Australian higher education students go overseas to receive a part of their education. This is a relatively new field in the Australian Higher Education literature. Although there have been a few schemes that enabled Australian university students to study overseas, the Australian Government launched its flagship OSM program, the New Colombo Plan (NCP) in 2013. With this recent shift, from West to East, in the direction of student mobility, the NCP encourages domestic Australian university students to participate in study exchange programs in Indo-Pacific and Asian region.

This is a qualitative study, which consists of document analysis and semi-structured interviews. For the document analysis section, the NCP is examined as the higher education policy, and Australian university students are interviewed as the third discourse contributing to OSM.

\section{Literature Review}

The literature review concentrates on the higher education student mobility programs. This paper, however, aims to shed light onto the relationship between the academic literature and the history of university policies.

Briefly, the study points out the focus of the literature being on the benefits of outbound mobility. For example, according to Bentley and Broons (1999), international experience is beneficial for students to be able to work in multicultural workplaces. International experience, as it is argued, beneficial because the programs are broadening their mind and re-defining their social identities (Lambert 1989). However, information in the Australian higher education literature regarding outbound mobility is still limited. Additionally, it is reported that Australian university student numbers, attending to outbound mobility programs are low (Daly and Barker 2005; Olsen 2008; Doyle et al. 2010; Daly 2011).

On the other hand, Rizvi (2011) points out to another interesting point to be taken into account. He suggests that studying abroad is not a new practice (Rizvi 2011). It is, in fact, a historical phenomenon, well established at least since the Middle Ages in the European context and even earlier in the Middle East and Eastern contexts (Guruz 2008). Despite the historical development of the concept of outbound mobility, it is a relatively new development in Australia. So too, recently, there is a shift towards outbound mobility in Australian universities, and our domestic students are encouraged to do a part of their study overseas.

Consequently, there has been an emerging Australian higher education literature; however, it requires attention in both social aspects and policy development in outbound mobility. On the social side, the literature assumes inherent and obvious benefits of mobility programs, and much of the literature overlooks the issues of students' existing cultural identities. (Crossman and Clarke 2010; Clifford 2011). However, the policy seemed to have concentrated on 
the aspects of economy and the Australian public diplomacy. Therefore, it is important to examine the development of mobility policies and to examine the underpinning motives of implementing these programs. For example, Rizvi (2011) argues that initiatives such as the Colombo Plan were originally designed and introduced as foreign aid programs and further argues that the aim of these programs were linked to a far deeper stated public diplomacy issues in the past. Similarly, Manathunga (2004) critiques these international education policies by drawing attention to the Original Colombo Plan's so-called 'peace building' Western imperialistic agenda. This paper only concentrates on the policy development and how it is analyzed in the research project. However, the overall project has a broader scope.

In consideration of the different focuses of both academic and policy discourses on the same educational programs, including Australian university students' perspectives to these discourses, however limited, seemed justifiable. Below, the overall research and its significance are presented. However, this paper reports on the policy aspect, which elaborates on the employed theories, methods and techniques.

\section{Research Questions}

The main question of this study is: How are the competing discourses of the New Colombo Plan funded Outbound Student Mobility Programs compared? The thesis takes the reader through different major stages and reports each stage as a separate chapter. In order to assist the main question, sub-questions are examined. In this paper, only the first sub-question is presented, which is "How have the mobility programs and the policies changed over time?" In order to explain this, the project conducted policy analysis.

\section{The Significance of the Study}

Overall, this project contributes to the existing knowledge of Australian OSM programs, particularly considering the emphasis given on these programs by the NCP policy. As mentioned, the emphasis on outbound mobility is a relatively new development in Australia, which was initiated by the NCP policy in 2013. By examining the policy, this study, a) highlights the emerging discourse of the policy, b) offers an opportunity to compare and contrast the aims and objectives of these programs with other discourses, such as the academic discourse, c) tackles the hidden neo-liberal

market agendas and neo-colonial aims embedded in recent government initiatives, d) aims to offer practical outcomes to optimize educational outcomes.

\section{Theoretical Framework and Methodology}

Overall, this qualitative study examines OSM through a combination of postcolonial and Foucauldian theories. This paper concentrates on the policy analysis aspect of the project, which is conducted by the guidance of Bacchi's (2009) 'What's the Problem Represented to be?' (WPR) approach. WPR is a specific policy analysis template, which is constructed in the poststructural/Foucaldian framework and consists of a number of questions in order to analyze a policy. Since WPR approach is both theoretical and methodological, specifying methodology and methods in the same section is deemed justifiable. Foucauldian-based approach to policy analysis asks six main questions, which are as follows:

1. What's the problem represented to be in a specific policy or a policy proposal?

2. What presuppositions or assumptions underpin this representation of the problem?

3. How has this representation of the problem come about? 
4. What is left unproblematic in this problem representation? Where are the silences? Can the problem be thought differently?

5. What effects are produced by this representation of the problem?

6. How/where has this representation of the problem been produced, disseminated and defended? How has it been (or could it be) questioned, disrupted and replaced?

The analysis is conducted by answering the questions presented above. Due to the scope of this paper, it is not possible to present the entire chapter or analysis here. However, it is possible to briefly mention the key tenets of Bacchi's (2009) approach. She argues that policies are based on 'problematization' concept. This means that policies are written in order to offer a solution to a socially-related problem. However, these 'problems' are constructed by policy makers in particular ways to serve the interest of particular groups in society. For example, through WPR policy analysis, my study concludes that in the case of Australian OSM programs, global citizenship, employability and international experience are some of the 'assumed' benefits and offered solutions to graduates' 'employability' anxieties for their life after post-graduation. However, the project demonstrates that the students do not necessarily acknowledge such benefits.

\section{The Overall Significance and the Contribution of this Study}

The project, overall, aims to draw attention to the discrepancies between discourses emerging from three different agents: the scholarly literature, the government policy, and the Australian university students. Considering the lack of student voices in the literature (Gargano 2009), the project contributes to the knowledge by delivering students' perspectives and by this, paving the way for more student-friendly discourses to emerge. For example, this study brings a fresh perspective because it considers mobility programs through the eyes of students, both mobile and nonmobile. Despite the emphasis on 'claimed benefits' and efforts of presenting Australian OSM programs as practical solutions to problems, such as employability, the projects tackle such market appeal. In fact, by contrast, this project takes a critical approach that draws attention to shortcomings of Australian OSM programs in order to offer and optimize more socially and culturally responsible policy and educational outcomes.

\section{References}

Arden, Mils., Catherine Manathunga and Dororthy Bottrell. 2017. "Identity construction through Australian university student mobility programs." In Student Culture and Identity in Higher Education, edited by A. Shahriar and G. Kazim,1-17. USA: IGI Global.

Bacchi, Carol. 2009. Analysing Policy: What's the problem represented to be?. Australia: Pearson Australia.

Crossman, Joanna Elizabeth and Marilyn Clarke. 2009. "International Experience and Graduate Employability: Stakeholder Perceptions on the Connection.” Higher Education 59(5): 599-613. https://doi.org/10.1007/s10734009-9268-z.

Daly, Amanda. 2011. "Determinants of participating in Australian university student exchange programs." Journal of Research in International Education 10(1): 58-70. doi:10.1177/1475240910394979.

Daly, Amanda and Meg Barker. 2005. "Australian and New Zealand University students' participation in nternational exchange programs." Journal of Studies in International Education 9(1): 26-41.

Doyle, Stephanie., Philip Gendall, Luanna H. Meyer, Janet Hoek, Carolyn Tait, Lyanne McKenzie and Avatar Loorparg. 2010. "An investigation of factors associated with student participation in study abroad." Journal of Studies in International Education 14(5): 471-490. doi:10.1177/1028315309336032. 
Gargano, Terra. 2009. "(Re)conceptualizing international student mobility: The potential of transnational social fields." Journal of Studies in International Education 13(3): 331-346.

Lambert, Richard D. 1998. International studies and undergraduate. Washington, DC: American Council on Education.

Manathunga, Catherine. 2014. "Discourse about war and peace in the Colombo Plan in Aetearoa/New Zealand". Victoria University.

Olsen, Alan. 2008. "International mobility of Australian University students: 2005." Journal of Studies in International Education 12(4): 364-374. doi:10.1177/1028315308314939.

Rizvi, Fazal. 2011. 'Theorizing student mobility in an era of globalization." Teachers and Teaching: Theory and Practice 17(6): 693-701. 